\title{
Comorbidity in Atopic Dermatitis
}

\author{
Eric L. Simpson
}

Published online: 20 January 2012

(C) Springer Science+Business Media, LLC 2012

\begin{abstract}
The negative impact of atopic dermatitis (AD) often extends beyond the skin. Children with $\mathrm{AD}$ experience increased rates of infectious, mental health, and allergic diseases compared to their non-atopic peers. The mechanisms underlying these associations remain elusive. New insights from genetic and epidermal research pinpoint the skin barrier as a primary initiator of AD. Epicutaneous sensitization represents an intriguing new model that links a disrupted skin barrier to the later development of IgE-mediated diseases in patients with AD. Recent epidemiologic studies have identified new comorbidities linked to $\mathrm{AD}$ as well, including several mental health disorders and obesity. This article reviews the recent literature regarding both classic and newly described $\mathrm{AD}$ comorbidities.
\end{abstract}

Keywords Comorbidity A Atopic dermatitis · Epicutaneous sensitization S Skin barrier - Eczema $\cdot$ Asthma $\cdot$ Attentiondeficit-hyperactivity-disorder · Eczema · Food allergy Cancer-Depression - Autism

\section{Introduction}

Atopic dermatitis (AD) is the most common chronic disease in childhood and has a prevalence ranging between $10 \%$ and $20 \%$ in many industrialized countries around the globe [1]. The prevalence is also rising in many developing countries

E. L. Simpson $(\bowtie)$

Department of Dermatology (CH16D),

Oregon Health \& Science University,

3303 SW Bond Avenue,

Portland, OR 97239-4501, USA

e-mail: simpsone@ohsu.edu
[2]. Although genetic skin barrier defects and immune hyper-responsiveness certainly are important to the pathogenesis of this disease, environmental factors are likely responsible for its rising prevalence and geographic variability. Patients with AD have chronically inflamed skin lesions that cause unrelenting pruritus, the primary source of morbidity in this disorder. The majority of patients with $\mathrm{AD}$ have mild disease, but even mild disease negatively affects a child's quality of life [3]. Childhood quality of life worsens with the severity of the skin disease [3]. Generalized AD negatively affects a child as much, or more, than other chronic diseases of childhood, such as asthma, diabetes, and chronic renal disease [4]. Having a child with $\mathrm{AD}$ also affects a whole family and may impact a family to a greater degree than having a child with type 1 diabetes [5].

The development of AD often heralds the beginning of the "atopic march," a term used to describe the increased risk these children have of developing one or more of the atopic diseases, which include asthma, food allergy, and allergic rhinitis $[6,7 \bullet \bullet, 8,9]$. AD usually precedes these atopic conditions, with over $60 \%$ of cases beginning within the first year of life [10]. The mechanisms by which $\mathrm{AD}$ leads to other atopic disorders are subjects of great current interest. $\mathrm{AD}$ also predisposes an individual to recurrent skin infections, either bacterial or viral. Recent studies also reveal children with $\mathrm{AD}$ are predisposed to the development of mental health disorders such as attention deficit hyperactivity disorder (ADHD), anxiety, and depression [11, 12•].

In the following review, recent developments in both the classic and newly described comorbidities associated with $\mathrm{AD}$ are presented. Focus is placed on studies published in the past year highlighting systematic reviews and cohort studies, when available, as they provide higher levels of evidence than other study types. 


\section{The Atopic March}

Atopic disease generally refers to having any one of the following conditions: asthma, food allergy, allergic rhinitis, or $\mathrm{AD}$. In general, the first of the atopic diseases to develop is $\mathrm{AD}$, followed shortly thereafter by food allergy, then asthma, and finally allergic rhinitis [8]. There is a significant body of epidemiologic evidence, including birth cohort studies, to support this sequence of disease progression $[6$, 9]. A few caveats arise regarding the relationship between $\mathrm{AD}$ and allergic disorders. First, an individual patient may display variability in which atopic conditions develop and in what sequence they arise. Secondly, the association between $\mathrm{AD}$ and allergic diseases may not even exist in developing countries. Results from the International Study of Asthma and Allergies in Childhood study covering 20 countries and over 28,000 children found the association between flexural eczema and skin prick positivity was strong in affluent countries but was absent in less affluent countries [13].

\section{Mechanisms Underlying the Atopic March}

\section{The Hygiene Hypothesis}

Research prior to 2006 primarily explored the hygiene hypothesis as a potential mechanism linking $\mathrm{AD}$ and other atopic diseases. The hygiene hypothesis states that atopic diseases result from reduced microbial exposure during early childhood, leading to the defective development of the immune system. Possibly, lack of exposure to microbial products such as endotoxin skews the immune system toward Th2 responses upon exposure to environmental allergens. This immunologic skewing predisposes individuals to develop diseases characterized by immunoglobulin E ( $I g E)$ sensitization and inflammation under the influence of interleukin (IL)-4, IL-5, and IL-13. Epidemiologic data in support of this theory have been inconsistent, but studies of atopic disease prevalence consistently show an urban-torural gradient, suggesting some exposure in the early rural environment may be protective [14-16].

\section{The Skin Barrier}

Recently, the finding that mutations in the epidermal gene, filaggrin, predispose to the development of $\mathrm{AD}$ and asthma provides a new possible explanation for the link between $\mathrm{AD}$ and allergic diseases [17]. Mutations in filaggrin are considered one of the strongest risk factors for any disease that has a complex inheritance pattern $[18 \bullet \bullet$. This discovery represents a marked shift away from previous thinking of atopic disease as being primarily immunologic in origin $[18 \bullet \cdot$. Patients with AD and concomitant filaggrin defects have disease that is earlier in onset, of greater severity, and that is more often accompanied by IgE sensitization compared to those with no filaggrin gene mutations [19].

Although the mechanisms explaining how filaggrin deficiency leads to skin inflammation are becoming clear, the link between filaggrin defects and allergic disease is still subject to conjecture. Filaggrin deficiency clearly leads to a xerotic barrier, primarily due to a reduction in natural moisturizing factor - a product of filaggrin proteolysis [20]. Filaggrin deficiency also leads to an elevated skin $\mathrm{pH}$, leading to additional downstream consequences on barrier function including altered lipid transport into the interstitial spaces of the stratum corneum and serine protease activation [21•]. Mouse models can help us understand how this altered barrier then leads to other allergic diseases. As expected, filaggrin knockout mice display skin that has a dry, disrupted barrier, but they also display enhanced Th2 responses and enhanced $\operatorname{IgE}$ production upon epidermal antigen challenge [22]. A knockdown in vitro model of filaggrin deficiency also shows enhanced thymic stromal lymphopoietin (TSLP) responses [23]. TSLP is a newly characterized cytokine that links the skin barrier and systemic allergic responses [24]. TSLP is produced by keratinocytes and promotes the development of Th2 lymphocytes and is upregulated in AD lesional skin. Overexpression of epidermal TSLP in mouse models leads to asthma phenotypes [25•]. Several other mouse models confirm this concept of epicutaneous sensitization, an intriguing model that links an epidermal defect with altered systemic immune responses and the future development of allergic disease [26-29].

\section{Asthma and Allergic Rhinitis}

Similar to AD, the global burden of asthma continues to rise, especially in developing countries [30]. Results from cohort studies consistently show children with $\mathrm{AD}$ are at an increased risk for the future development of asthma and allergic rhinitis [31]. Risk factors for the development of asthma in children with $\mathrm{AD}$ include persistent or more severe $\mathrm{AD}, \operatorname{IgE}$ sensitization, and filaggrin deficiency [9, 17, 32, 33]. Gustafsson et al. [34] found that in children with severe $\mathrm{AD}, 50 \%$ developed asthma and $75 \%$ developed allergic rhinitis. Filaggrin deficiency, even in the absence of $\mathrm{AD}$, may increase the risk for asthma development and influence asthma severity $[35,36]$, supporting the idea of epicutaneous sensitization.

A systematic review of cohort studies quantified the risk of developing asthma in children with AD [6]. They found the prevalence of asthma in children with $\mathrm{AD}$ ranges between $14.2 \%$ and $52.7 \%$. The odds ratio for developing asthma in children with $\mathrm{AD}$ was 2.14 (95\% CI, 1.67-2.75) 
compared to children without AD. Although significant, this risk was lower than previously thought. The true risk in the general population may actually be even lower, as several of the cohort studies included in this study were hospitalbased. The risk of developing new-onset asthma may persist beyond 6 years of age. Data from the Tasmanian Longitudinal Health study demonstrated the risk of developing asthma in children with AD persists into adulthood [37], although data from the Tucson's Children Respiratory study did not confirm this finding [38].

Most previous studies of asthma in AD do not specify the type of asthma that develops in the context of $\mathrm{AD}$. A movement towards classification of asthma according to pathophysiology is underway, as many different mechanisms may drive common asthma phenotypes [39]. Follow-up of the Tasmanian Longitudinal Health Study found that childhood $\mathrm{AD}$ increased the risk of persistent allergic asthma as an adult (defined as asthma plus one skin prick test positive) but not non-allergic asthma [40]. This group also found the presence of concomitant $\mathrm{AD}$ and allergic rhinitis increased the risk of developing allergic asthma above having AD alone (OR 6.3; 95\% CI, 1.723.2). This combination of diseases was responsible for up to $30 \%$ of all allergic asthma cases in the population sample. Better clarification of the type of asthma that develops in the context of AD aids in our understanding of the atopic march and may have therapeutic implications. For example, allergic asthma may respond to anti-IL-5 therapy or other Th2 cytokine blockade more effectively than non-allergic asthma subtypes [39].

\section{Food Allergy}

The relationship between food allergy and the eczematous lesions in $\mathrm{AD}$ is controversial. More relevant to an understanding of comorbidity in AD is the well-established increase in the prevalence of type I hypersensitivity reactions to foods in patients with AD. Determining an accurate prevalence of clinically significant food reactions in patients with AD has been difficult.

A recent systematic review by Chafen et al. concluded that the literature regarding food allergy in general, although voluminous, was significantly limited by the lack of uniformity in disease definitions [41]. Early studies in patients with $\mathrm{AD}$ demonstrated a $37 \%$ to $39 \%$ prevalence of type I reactions to food allergens in patients with $\operatorname{AD}[42,43]$, with one study reporting a $60 \%$ prevalence [44]. These studies likely overestimate the true prevalence of food allergy in $\mathrm{AD}$, as they were performed in tertiary care centers and involved patients with more severe $\mathrm{AD}$. The prevalence of type I food reactions in a community-based sample of patients with $\mathrm{AD}$ is unknown. A recent clinical trial that recruited infants with mild-to-moderate disease from the general population found $15.7 \%$ of subjects experienced convincing food reactions by age 3 years, although no food challenges were performed [45]. Another recent populationbased study, using data from the 2005-2006 National Health and Nutrition Examination Survey (NHANES), did not find patient-reported eczema to be more prevalent in those with food allergy using adjusted models that included demographic variables and inhalant sensitization status [46].

Although the risk of food allergy is significant in patients with moderate-to-severe $\mathrm{AD}$, the results of two recent studies suggest a significant portion of morbidity stems from the misinterpretation of allergy tests by well-meaning clinicians. Fleisher et al. [47•] found $89 \%$ of oral food challenges were negative for type I reactions in children with $\mathrm{AD}$ when challenged with foods they were avoiding based on the results of immunoassay or skin prick testing [47]. In addition, no late reactions such as eczema flares were witnessed on examination the next day or 1 week later. The majority of children $(66 \%)$ in this study had moderate-to-severe $\mathrm{AD}$ the population most at risk for food allergy. Children did not receive oral food challenges if they had a history of lifethreatening reactions or had a "convincing history" of a reaction occurring in the previous 12 months. These results were similar to a smaller study by Rowlands et al. [48] reported previously [48]. Sinagra et al. [49] evaluated 186 consecutive children with $\mathrm{AD}, 24 \%$ of whom were on milkelimination diets primarily on the advice of their clinicians. All patients received an allergy evaluation that included both skin prick testing and serum immunoassay evaluation. Of the children on milk-elimination diets, only $9 \%$ had positive reactions to oral food challenges. This equated to an overall $2 \%$ prevalence of milk allergy in the unselected sample of children with $\mathrm{AD}$. No late eczematous reactions were observed in challenged patients when examined after 3 days.

There are several clinical implications of this recent work. These studies suggest children with AD should not be routinely placed on restricted diets without confirmation by allergy testing. Unless a history of immediate type I symptoms can be elicited, routine allergy testing (serum or skin prick) should be avoided, as the positive predictive values are very low and the results often lead to unnecessary elimination diets. The negative effects of unnecessary elimination diets extend beyond mere inconvenience, as some children develop severe malnourishment because of presumed food allergy. Pellagra, rickets, and kwashiorkor have all been reported due to inappropriate dietary restriction due to food allergy concerns [50-52]. The National Institute for Allergy and Infectious Disease published guidelines in 2011 regarding the diagnosis and management of food allergy after an extensive systematic review of the literature [53•]. The expert panel, consisting of both allergists and dermatologists, 
recommended that allergy-based testing only occur in children with $\mathrm{AD}$ if one of two conditions is met: 1) the patient is not responding adequately to optimized skin-directed therapies or 2 ) the child has a convincing history of a type I food reaction such as a history of lip swelling, vomiting, or urticaria within $2 \mathrm{~h}$ of eating a food. They identified egg, peanut, milk, wheat, and soy as the most common allergenic foods in this population. Children with clinically significant food allergy will often develop tolerance over time to milk, egg, soy, and wheat, so they should be retested as they grow older.

\section{Infections}

Patients with $\mathrm{AD}$ are susceptible to developing a variety of cutaneous infections, including bacterial, viral, and fungal. Defects in cell-mediated immunity, such as blunted Th1 responses, are thought to be responsible for this predisposition. Defects in the skin barrier, such as altered antimicrobial peptide profiles and filaggrin deficiency, may also explain this susceptibility $[54,55]$. Although most clinicians agree that infectious complications occur frequently in patients with $\mathrm{AD}$, the epidemiologic evidence supporting this association is relatively weak. Recently, a comprehensive study examining infectious complications in $\mathrm{AD}$ was performed by Hayashida et al. [7••]. Using a population-based sample of schoolchildren in Ishigaki City, Japan, they confirmed that children with $\mathrm{AD}$ have an increased lifetime prevalence of impetigo contagiosum (OR 1.80; 95\% CI, 1.16-2.8). They did not find an association between $\mathrm{AD}$ and molluscum or herpes infections.

\section{Bacterial}

Staphylococcal skin infections are the most important infectious complication in $\mathrm{AD}$, given its high prevalence. Staphylococcal bacteria secrete enterotoxins and superantigens that exacerbate skin inflammation [56]. Worsening of inflammation may further downregulate barrier function and blunt antimicrobial peptide production, creating the ideal environment for continued Staphylococcus aureus infection [57]. Up to $90 \%$ of patients with AD are colonized with $S$. aureus either in the nares or skin and are colonized in sites not typically seen in non-AD patients [58-60]. Good prospective data regarding incident rates of $S$. aureus infection in $\mathrm{AD}$ are lacking. One exception is the population-based study by Hayashida et al. [7•0] mentioned previously that found children with a history of $\mathrm{AD}$ reported an episode of impetigo contagiosum (OR 1.8; 95\% CI, 1.16-2.81) more often than those without AD. Data regarding the prevalence of methicillin-resistant S. aureus (MRSA) colonization and infection in the AD population are also sparse and conflicting. Early hospital-based studies reported elevated
MRSA colonization rates [61, 62], whereas more recent studies do not confirm increased MRSA colonization in patients with $\mathrm{AD}[63,64]$.

Treatment of S. aureus infections in $\mathrm{AD}$ should be reserved for clinically infected lesions. In our practice, we find limiting oral antibiotic courses to 5 days of therapy reduces the risk for antibiotic resistance and is sufficient to control most superficial infections. Experimental data support this clinical observation. An in vitro model of $S$. aureus killing by quinolone therapy shows resistant organisms increase by day 4 of therapy [65]. Clinical studies are ultimately needed to determine the optimal management of recurrent $S$. aureus infection in $\mathrm{AD}$. A recent systematic review failed to find any benefit of various other antimicrobial modalities, including cleansers, combination topical therapies, or textiles, in the treatment of infected $\mathrm{AD}$ [66]. Although the treatment of uninfected $\mathrm{AD}$ with antibiotics does not improve outcomes, a recent study using a dilute sodium hypochlorite bath improved disease outcomes by presumably reducing $S$. aureus colonization [67]. More studies of this inexpensive modality are eagerly awaited.

\section{Viral}

Although the epidemiologic evidence for an increased risk of routine viral infections in patients with $\mathrm{AD}$ is limited [7 $\bullet$, $68,69]$, patients with $\mathrm{AD}$ at the very least develop exaggerated clinical manifestations of viral infection, including giant and widespread molluscum, eczema vaccinatum, and eczema herpeticum. Most dramatic among these is eczema vaccinatum (EV), a rare consequence of smallpox vaccination with an incidence estimated at 12.8 per 1 million vaccinations [70]. Death occurs in approximately $3 \%$ of people who develop EV, with all deaths occurring in individuals that acquired $\mathrm{EV}$, not through direct vaccination, but via contact transmission from a recent vaccine [66]. Although routine smallpox vaccinations were halted in the United States in 1972, smallpox vaccinations were reinstituted among military personnel in 2002. Contraindications for receiving the smallpox vaccine include a history of current or past $\mathrm{AD}$ or having a household contact with an individual with $\mathrm{AD}$. The ability for vaccinees to correctly identify these contraindications is poor, however [71], and new cases of EV are now emerging [72, 73]. A new smallpox vaccine using a replication-incompetent modified vaccinia virus has shown preliminary safety and efficacy in patients with AD [74]. Treatment options for EV include vaccinia immune globulin, cidofovir, or tecovirimat (a new antiviral with specific antiviral activity against orthopox viruses) [75].

Eczema herpeticum (EH), although rare, is another important example of an exaggerated clinical viral infection in patients with $\mathrm{AD}$. One study found a history of $\mathrm{EH}$ to occur 
in less than $3 \%$ of tertiary referral patients with $\mathrm{AD}[76]$. Classic EH presents with diffuse vesicles spreading beyond the initial site of infection and accompanied by fever and lymphadenopathy. EH may be complicated by herpetic keratitis, or even viral dissemination and death [77, 78]. Atypical presentations of EH are common, with pustules or crusts mimicking S. aureus infection [79]. The Atopic Dermatitis Vaccinia Network (ADVN) is a network of researchers funded by the National Institutes of Health, whose objective is to investigate the mechanisms underlying viral infection susceptibility in AD [80]. This group discovered patients with $\mathrm{EH}$ have more severe underlying $\mathrm{AD}$, more IgEmediated diseases, and a higher susceptibility to other types of cutaneous infections [80]. Mechanisms underlying the susceptibility to EH discovered by this group include altered interferon- $\gamma$ responses and genetic defects in filaggrin, the tight junction protein claudin-1, and TSLP $[47 \cdot, 81,82$, 83•].

\section{Fungal}

Patients with AD may have an increased susceptibility to dermatophyte fungal infections [84], but the data are conflicting [85]. Older literature suggests that patients with $\mathrm{AD}$ may have more chronic dermatophytosis and have reduced trichophytin reactivity $[86,87]$. Prospective studies are needed to better define this association using modern epidemiologic approaches and improved disease definitions. The majority of current research regarding fungal organisms in $\mathrm{AD}$ revolves around the causal role of Malassezia species (formerly known as Pityrosporum) in AD [88], which has yet to be established. Antifungal agents have been used in patients with $\mathrm{AD}$, especially those with prominent head and neck involvement, with mixed results [89].

\section{Mental Health}

A recognized link between $\mathrm{AD}$ and one's emotional and mental state dates back to the early 1900s, when AD was termed "neurodermatitis" [90]. In the 1950s, AD was considered a classic psychosomatic disorder [91, 92]. Controlled studies beginning in the 1980s confirmed that children with $\mathrm{AD}$ demonstrate psychological disturbances more frequently than do their healthy peers [93-95], and that this association correlates with the severity of the skin disease [94]. Having a child with AD negatively affects the mental state of parents as well. Mothers of children with AD report higher stress levels, less employment, more difficulty with child discipline, and a lack of social support networks compared to parents in a control group [96]. In 1991, Roth et al. [97] found that children with $\mathrm{AD}$ have attention problems and restlessness and meet criteria for attention deficit hyperactivity disorder
(ADHD) at higher rates than a control population. Not until more than a decade after this initial observation did subsequent studies confirm an association between $\mathrm{AD}$ and $\mathrm{ADHD}$ in larger populations [12•].

\section{Attention Deficit Hyperactivity Disorder}

Schmitt et al. [12•] performed the first population-based study evaluating the relationship between AD and ADHD and found a significant association (OR 1.47; 95\% CI, 1.01$2.15)$, even when controlling for confounding variables such as age, sex, and other mental health disorders. The same German research group confirmed this relationship in another cross-sectional study from a separate population and again found an association between AD and ADHD (OR $1.54 ; 95 \%$ CI, 1.24-1.93), with a stronger association seen in children with reported sleep problems (OR 2.67; 95\% CI, 1.51-4.71) [98]. A systematic review of all cross-sectional studies (six papers, all from Europe) calculated that $9 \%$ of the total ADHD burden in Europe may be attributable to AD [99]. Two recent cohort studies from Germany established a temporal association lacking in previous cross-sectional studies between AD in early childhood and the presence of emotional and conduct problems at age $10[100,101]$. Our group has recently presented data confirming the association between $\mathrm{AD}$ and ADHD using population-based data of over 90,000 children in the United States [102]. We found a dose-dependent relationship between the reported severity of $\mathrm{AD}$ and the prevalence of ADHD, suggesting a causal relationship.

\section{Other Mental Health Outcomes}

Several studies have shown an association between atopic disease and anxiety, depression, and autism [11, 94, 103]. Spring-time worsening of autism symptoms has also been reported, suggesting a link between respiratory allergies and autism [104]. Three recent cross-sectional studies have found strong associations between a history of atopic disease and the presence of autism [105-107]. These studies are limited by the combining of all atopic disorders together in analyses. Recently, studies have examined the mental health effects of AD separated out from other atopic diseases. Using a population-based sample from the United States, Yang et al. [108] found an increased likelihood of a depressive disorder in adults with $\mathrm{AD}(\mathrm{OR}>2.0)$, and a controlled study from Germany found increased rates of anxiety, depression, and suicidal ideation in adults with $\mathrm{AD}$ that correlated with disease severity [109]. Our group recently confirmed the association between $\mathrm{AD}$ and other mental health disorders, including anxiety, depression, conduct disorder, and autism, in a large US pediatric population [102]. 


\section{Proposed Mechanisms}

Chronic sleep disturbance secondary to nocturnal pruritus and the effects of proinflammatory cytokines on brain development are two leading hypotheses explaining why children with $\mathrm{AD}$ develop mental health disorders later in life. Disrupted sleep patterns have well-known negative effects on the mental state of healthy children, including effects on behavior, school functioning, attention, and mood [110-112]. Similarly, disrupted sleep patterns have been found significantly more frequently among youth with depression, anxiety, ADHD, and autism than among youth without such mental health disorders $[113,114]$. The second hypothesis involves the role inflammatory mediators may play in psychiatric and neurodevelopmental conditions. The presence of cytokines and cytokine receptors in the fetal brain argue that these substances play a role in early brain development [115]. Previous clinical investigations have demonstrated a link between proinflammatory cytokines and depression, anxiety, and autism [116-118]. Associations between proinflammatory cytokines and psychological functioning in patients with atopic diseases have also been demonstrated [119]. Recently, a hypothesis was advanced that a "cytokine storm" in early fetal development may promote the development of autism [120].

\section{Cancer}

Older literature suggests having atopic disease decreases one's risk of a variety of cancers [121]. The protective effect of atopic disease was thought to stem from enhanced immune surveillance as a consequence of a proinflammatory state. A systematic review in 2006 examining the cancer risk associated with $\mathrm{AD}$ found fairly consistent evidence for a protective effect of $\mathrm{AD}$ on the development of pancreatic cancer, brain tumors, and childhood leukemia [122]. This review, however, was limited by a lack of formal metaanalyses and the overall poor quality of reporting in the individual studies.

More recent data suggest a more mixed picture, with the protective effects of various atopic diseases being specific to cancer type [123]. In addition, some other studies have found increased rates of a variety of cancers in patients with a history of $\mathrm{AD}$, including cutaneous $\mathrm{T}$ cell lymphoma and brain cancer [124-126]. A review by Tennis et al. [127] concluded that the risk of lymphoma is likely increased in $\mathrm{AD}$, especially in those patients with severe disease. Commentaries by Wedgeworth et al. [128, 129] nicely review the literature and identify the weaknesses common to previous studies of $\mathrm{AD}$ and cancer risk. For example, recall bias and ascertainment bias may explain some of the observed associations. Exposure and outcome variables are often poorly defined and are not validated. Confounding factors, such as the effect of $\mathrm{AD}$ treatment on cancer risk, are often not considered. Given these limitations in the literature and mixed results of studies, it is difficult to draw general conclusions regarding the cancer risk in AD. If an association does exist between $\mathrm{AD}$ and cancer, it is likely to be cancerspecific with a small effect size.

\section{Obesity}

Elevated serum levels of IL-6, tumor necrosis factor- $\alpha$ (TNF- $\alpha)$, and inflammatory markers such as C-reactive protein suggest obesity is a proinflammatory state [130]. Based on these observations, an increased incidence of inflammatory diseases would be expected following the development of childhood obesity. Indeed, many studies link obesity to the development of autoimmune as well as atopic disorders [131-136]. Previous studies of growth and $\mathrm{AD}$ actually found delayed growth in children with $\mathrm{AD}$, especially in patients with more severe disease [137-142]. Ellison et al. [143] more closely examined the pattern of height and weight change over time in children with AD and found young children with AD were shorter and more overweight than a reference population in the United Kingdom [143]. Although median body mass indices were similar in the older age groups, a delayed adolescent growth spurt was observed in the AD group [143]. Most recently, two studies have found an association between early childhood obesity and AD. A case-control study found obesity prior to the age of 2 years and obesity that lasted longer than 2.5 years were associated with AD development [144]. The presence of obesity also predicted a more severe dermatitis course. In a cross-sectional study of patients attending an allergy clinic, the prevalence of obesity was higher in the subset of AD patients with concomitant allergic sensitization than in those patients without a history of AD [145]. Although this recent work potentially identifies a modifiable risk factor for $\mathrm{AD}$ development, not all studies have confirmed the relationship between obesity and AD [134, 146, 147]. Investigations using population-based cohorts are needed to further evaluate this association.

\section{Conclusions}

We are entering an era of dermatologic research that extends the scope of investigation beyond the skin. Emerging comorbidities in AD identified by epidemiologic research include a variety of mental health disorders and obesity. These newly described associations need confirmation from more sophisticated investigation using cohort study designs and validated disease definitions. Our new understanding of the importance of the skin barrier in $\mathrm{AD}$ initiation helps us 
understand potential mechanisms involved in the development of the comorbidities associated with the atopic march. Identification of new comorbid conditions is important, but future work should investigate potential strategies to mitigate the development of these various comorbidities in $\mathrm{AD}$. In addition, studies should evaluate the effects that early aggressive therapy or atopic prevention strategies may have on the development of subsequent comorbid conditions.

Acknowledgments I would like to thank my mentor, Jon Hanifin, MD for his critical review of the manuscript, and Renato Goreshi, MD and Christine E. Carocci for their editorial assistance. This project was supported by grant number 5K23AR057486-02 from the National Institutes of Health.

Disclosure E.L. Simpson has received a grant (payable to his institution) from the National Institutes of Health.

\section{References}

Papers of particular interest, published recently, have been highlighted as:

- Of importance

•- Of major importance

1. Odhiambo JA, Williams HC, Clayton TO, et al. ISAAC Phase Three Study Group. Global variations in prevalence of eczema symptoms in children from ISAAC phase three. J Allergy Clin Immunol. 2009;124(6):1251-1258.e23.

2. Williams H, Stewart A, von Mutius E, et al. (International Study of Asthma and Allergies in Childhood (ISAAC) phase one and three study groups): is eczema really on the increase worldwide? J Allergy Clin Immunol. 2008;121(4):947-954.e15.

3. Ben-Gashir MA, Seed PT, Hay RJ. Quality of life and disease severity are correlated in children with atopic dermatitis. Br J Dermatol. 2004;150:284-90.

4. Beattie PE, Lewis-Jones MS. An audit of the impact of a consultation with a paediatric dermatology team on quality of life in infants with atopic eczema and their families: further validation of the Infants' Dermatitis Quality of Life Index and Dermatitis Family Impact score. Br J Dermatol. 2006;155(6):1249-55.

5. Su JC, Kemp AS, Varigos GA, et al. Atopic eczema: its impact on the family and financial cost. Arch Dis Child. 1997;76(2):15962.

6. van der Hulst AE, Klip H, Brand PL. Risk of developing asthma in young children with atopic eczema: a systematic review. J Allergy Clin Immunol. 2007;120(3):565-9.

7. • Hayashida S, Furusho N, Uchi H, et al. Are lifetime prevalence of impetigo, molluscum and herpes infection really increased in children having atopic dermatitis? J Dermatol Sci. 2010 Dec;60 (3):173-8. This is a comprehensive, population-based approach to examining infections in AD. It helped fill a big gap in the literature.

8. Zheng T, Yu J, Oh MH, et al. The atopic march: progression from atopic dermatitis to allergic rhinitis and asthma. Allergy Asthma Immunol Res. 2011;3(2):67-73.

9. Spergel JM. From atopic dermatitis to asthma: the atopic march. Ann Allergy Asthma Immunol. 2010;105(2):99-106.

10. Williams HC (2000) Atopic dermatitis - the epidemiology, causes and prevention of atopic eczema. Cambridge University Press.
11. Slattery MJ, Essex MJ, Paletz EM, et al. Depression, anxiety, and dermatologic quality of life in adolescents with atopic dermatitis. J Allergy Clin Immunol. 2011;128(3):668-71.

12. - Schmitt J, Romanos M, Schmitt NM, et al. Atopic eczema and attention-deficit/hyperactivity disorder in a population-based sample of children and adolescents. JAMA. 2009 Feb 18;301 (7):724-6. The first article using a large database of patients to establish a link between AD and ADHD.

13. Flohr C, Weiland SK, Weinmayr G, et al. The role of atopic sensitization in flexural eczema: findings from the International Study of Asthma and allergies in childhood phase two. J Allergy Clin Immunol. 2008;121(1):141-7.

14. Flohr C, Pascoe D, Williams HC. Atopic dermatitis and the "hygiene hypothesis": too clean to be true? Br J Dermatol. 2005;152(2):202-16.

15. Shaw TE, Currie GP, Koudelka CW, Simpson EL. Eczema prevalence in the United States: data from the 2003 National Survey of Chilfren's Health. J Invest Dermatol. 2011;131(1):67-73.

16. Schram ME, Tedia AM, Tedja R, et al. Is there a rural/urban gradient in the prevalence of eczema? a systematic review. $\mathrm{Br} \mathrm{J}$ Dermatol. 2010;162(5):964-73.

17. Palmer CN, Irvine AD, Terron-Kwiatkowski A, et al. Common loss-of-function variants of the epidermal barrier protein filaggrin are a major predisposing factor for atopic dermatitis. Nat Genet. 2006;38(4):441-6.

18. •- Irvine AD, McLean WH, Leung DY. Filaggrin mutations associated with skin and allergic diseases. N Engl J Med. 2011 Oct;365(14):1315-27. This is a beautiful review of our current understanding of the role filaggrin plays in AD pathophysiology.

19. van den Oord RA, Sheikh A. Filaggrin gene defects and risk of developing allergic sensitisation and allergic disorders: systematic review and meta-analysis. Br Med J. 2009;339:b2433.

20. O'Regan GM, Kemperman PM, Sandilands A, et al. Raman profiles of the stratum corneum define 3 filaggrin genotypedetermined atopic dermatitis endophenotypes. J Allergy Clin Immunol. 2010;126(3):574-80.e1.

21. - Gruber R, Elias PM, Crumrine D, et al. Filaggrin genotype in ichthyosis vulgaris predicts abnormalities in epidermal structure and function. Am J Pathol. 2011 May;178(5):2252-63. This article is a comprehensive biophysical and electro-micrographic study of humans with defects in the filaggrin gene.

22. Fallon PG, Sasaki T, Sandilands A, et al. A homozygous frameshift mutation in the mouse Flg gene facilitates enhanced percutaneous allergen priming. Nat Genet. 2009;41(5):602-8.

23. Lee KH, Cho KA, Kim JY, et al. Filaggrin knockdown and tolllike receptor 3 (TLR3) stimulation enhanced the production of thymic stromal lymphopoietin (TSLP) from epidermal layers. Exp Dermatol. 2011;20(2):149-51.

24. Ziegler SF, Artis D. Sensing the outside world: TSLP regulates barrier immunity. Nat Immunol. 2010;11(4):289-93.

25. - Demheri S, Morimoto M, Holtzman M, et al. Skin-derived TSLP triggers progression from epidermal-barrier defects to asthma. PLoS Biol. 2009 May 19;7(5):e1000067. Epub 2009 May 19. This is an important mouse model that describes a mechanism by which AD may lead to asthma.

26. Wang L, Lin JY, Hsieh KH, et al. Epicutaneous exposure of protein antigen induces a predominant Th2-like response with high IgE production in mice. J Immunol. 1996;156(11):4077-82.

27. Spergel JM, Mizoguchi E, Brewer JP, et al. Epicutaneous sensitization with protein antigen induces localized allergic dermatitis and hyperresponsiveness to methacholine after single exposure to aerosolized antigen in mice. J Clin Invest. 1998; 101:1614-22.

28. Herrick CA, MacLeod H, Glusac E, et al. Th2 responses induced by epicutaneous or inhalational protein exposure are differentially dependent on IL-4. J Clin Invest. 2000;105:765-75. 
29. Briot A, Lacroix M, Robin A, et al. Par2 inactivation inhibits early production of TSLP, but not cutaneous inflammation, in Netherton syndrome adult mouse model. J Invest Dermatol. 2010;130(12):2736-42.

30. Pearce N, Ait-Khaled N, Beasley R, et al. Worldwide trends in the prevalence of asthma symptoms: phase III of the International Study of Asthma and allergies in childhood (ISAAC). Thorax. 2007;62(9):758-66.

31. Spergel JM. Epidemiology of atopic dermatitis and atopic march in children. Immunol Allergy Clin North Am. 2010;30(3):26980.

32. Illi S, von Mutius E, Lau S, et al. The natural course of atopic dermatitis from birth to age 7 years and the association with asthma. J Allergy Clin Immunol. 2004;113(5):925-31.

33. Meijer A. Asthma predictors in infantile atopic dermatitis. J Asthma Res. 1975;12(3):181-8.

34. Gustafsson D, Sjöberg O, Foucard T. Development of allergies and asthma in infants and young children with atopic dermatitis - a prospective follow-up to 7 years of age. Allergy. 2000;55:240-5.

35. Ponińska J, Samoliński B, Tomaszewska A, et al. Filaggrin gene defects are independent risk factors for atopic asthma in a Polish population: a study in ECAP cohort. PLoS One. 2011;6(2): e16933.

36. Palmer CN, Ismail T, Lee SP, et al. Filaggrin null mutations are associated with increased asthma severity in children and young adults. J Allergy Clin Immunol. 2007;120(1):64-8.

37. Burgess JA, Dharmage SC, Byrnes GB, et al. Childhood eczema and asthma incidence and persistence: a cohort study from childhood to middle age. J Allergy Clin Immunol. 2008;122(2):280-5.

38. Stern DA, Morgan WJ, Halonen M, et al. Wheezing and bronchial hyper-responsiveness in early childhood as predictors of newly diagnosed asthma in early adulthood: a longitudinal birth-cohort study. Lancet. 2008;372(9643):1058-64.

39. Lötvall J, Akdis CA, Bacharier LB, et al. Asthma endotypes: a new approach to classification of disease entities within the asthma syndrome. J Allergy Clin Immunol. 2011;127(2):355-60.

40. Martin PE, Matheson MC, Gurrin L, et al. Childhood eczema and rhinitis predict atopic but not nonatopic adult asthma: a prospective cohort study over 4 decades. J Allergy Clin Immunol. 2011;127(6):1473-9.e1

41. Chafen JJ, Newberry SJ, Riedl MA, et al. Diagnosing and managing common food allergies: a systematic review. JAMA. 2010;303(18):1848-56.

42. Eigenmann PA, Sicherer SH, Borkowski TA, et al. Prevalence of IgE-mediated food allergy among children with atopic dermatitis. Pediatrics. 1998;101(3):E8.

43. Burks W, James JM, Hiegel A, et al. Atopic dermatitis and food hypersensitivity reactions. J Pediatr. 1998;132(1):132-6.

44. Sampson HA, McCaskill CC. Food hypersensitivity and atopic dermatitis: evaluation of 133 patients. J Pediatr. 1985;107:669-75.

45. Hanifin JM, Boguniewicz M, Eichenfield LF, et al. A long-term study of safety and allergic comorbidity development in a randomized trial of pimecrolius cream in infants with atopic dermatitis. $\mathrm{J}$ Invest Dermatol. 2010;130(Supplement 1):S55. Abstract \#328.

46. Liu AH, Jaramillo R, Sicherer SH, et al. National prevalence and risk factors for food allergy and relationship to asthma: results from the National Health and Nutrition Examination Survey 20052006. J Allergy Clin Immunol. 2010;126(4):798-806.e13.

47. • Fleischer DM, Bock SA, Spears GC, et al. Oral food challenges in children with a diagnosis of food allergy. J Pediatr. 2011 Apr;158(4):578-583.e1. This article helps clarify the true risk of food reactions in AD with positive allergy tests.

48. Rowlands D, Tofte SJ, Hanifin JM. Does food allergy cause atopic dermatitis? food challenge testing to dissociate eczematous from immediate reactions. Dermatol Ther. 2006;19(2):97-103.
49. Sinagra JL, Bordignon V, Ferraro C, et al. Unnecessary milk elimination diets in children with atopic dermatitis. Pediatr Dermatol. 2007;24(1):1-6.

50. Tierney EP, Sage RJ, Shwayder T. Kwashiorkor from a severe dietary restriction in an 8-month infant in suburban Detroit, Michigan: case report and review of the literature. Int J Dermatol. 2010;49 (5):500-6.

51. Ladoyanni E, Cheung ST, North J, et al. Pellagra occurring in a patient with atopic dermatitis and food allergy. Eur Acad Dermatol Venereol. 2007;21(3):394-6.

52. Huang LT, Yang W, Wu CL. Vitamin D deficiency rickets due to inappropriate feeding: report of one case. Acta Paediatr Taiwan. 2000;41(3):151-4.

53. - NIAID-sponsored Expert Panel, Boyce JA, Assa'ad A, Burks $\mathrm{AW}$, et al. Guidelines for the diagnosis and management of food allergy in the United States: report of the NIAID-sponsored expert panel. J Allergy Clin Immunol. 2010 Dec;126(6 Suppl): $\mathrm{S} 1-\mathrm{S} 58$. This is an important systematic review with expert guidance involving dermatologists and allergists defining what "allergy" is and when to test patients with $A D$.

54. Ong PY, Ohtake T, Brandt C, et al. Endogenous antimicrobial peptides and skin infections in atopic dermatitis. N Engl J Med. 2002;347(15):1151-60.

55. Cai SC, Chen H, Koh WP, et al. Filaggrin mutations are associated with recurrent skin infection in Singaporean Chinese patients with atopic dermatitis. Br J Dermatol. 2011. doi:10.1111/j.13652133.2011.10541.x. Epub ahead of print.

56. Lin YT, Wang CT, Chiang BL. Role of bacterial pathogens in atopic dermatitis. Clin Rev Allergy Immunol. 2007;33(3):16777.

57. Howell MD, Boguniewicz M, Pastore S, et al. Mechanism of HBD-3 deficiency in atopic dermatitis. Clin Immunol. 2006;121 (3):332-8.

58. Leyden JJ, Kligman AM. The role of microorganisms in diaper dermatitis. Arch Dermatol. 1978;114(1):56-9.

59. Nishijima S, Namura S, Higashida T, et al. Staphylococcus aure$u s$ in the anterior nares and subungual spaces of the hands in atopic dermatitis. J Int Med Res. 1997;25(3):155-8.

60. Nakata K, Inoue Y, Harada J, et al. A high incidence of Staphylococcus aureus colonization in the external eyes of patients with atopic dermatitis. Ophthalmology. 2000;107(12):2167-71.

61. Klein PA, Greene WH, Fuhrer J, et al. Prevalence of methicillinresistant Staphylococcus aureus in outpatients with psoriasis, atopic dermatitis, or HIV infection. Arch Dermatol. 1997;133 (11):1463-5.

62. Chung HJ, Jeon HS, Sung H, et al. Epidemiological characteristics of methicillin-resistant Staphylococcus aureus isolates from children with eczematous atopic dermatitis lesions. Clin Microbiol. 2008;46(3):991-5.

63. Balma-Mena A, Lara-Corrales I, Zeller J, et al. Colonization with community-acquired methicillin-resistant Staphylococcus aureus in children with atopic dermatitis: a cross-sectional study. Int $\mathrm{J}$ Dermatol. 2011;50(6):682-8.

64. Matiz C, Tom WL, Eichenfield LF, et al. Children with atopic dermatitis appear less likely to be infected with community acquired methicillin-resistant Staphylococcus aureus: the San Diego experience. Pediatr Dermatol. 2011;28(1):6-11.

65. Drusano GL, Liu W, Brown DL, et al. Impact of short-course quinolone therapy on susceptible and resistant populations of Staphylococcus aureus. J Infect Dis. 2009;199(2):219-26.

66. Bath-Hextall FJ, Birnie AJ, Ravenscroft JC, et al. Interventions to reduce Staphylococcus aureus in the management of atopic eczema: an updated Cochrane review. Br J Dermatol. 2010;163(1):12-26.

67. Huang JT, Abrams M, Tlougan B, et al. Treatment of Staphylococcus aureus colonization in atopic dermatitis decreases disease severity. Pediatrics. 2009;123(5):e808-14. 
68. Currie JM, Wright RC, Miller OW. The frequency of warts in atopic patients. Cutis. 1971;8:244-5.

69. Solomon LM, Telner P. Eruptive molluscum contagiosum in atopic dermatitis. Can Med Assoc J. 1966;95(19):978-9.

70. Aragón TJ, Ulrich S, Fernyak S, et al. Risks of serious complications and death from smallpox vaccination: a systematic review of the United States experience, 1963-1968. BMC Publ Health. 2003;3:26.

71. Naleway AL, Belongia EA, Greenlee RT, et al. Eczematous skin disease and recall of past diagnoses: implications for smallpox vaccination. Ann Intern Med. 2003;139(1):1-7.

72. Moses AE, Cohen-Poradosu R. Images in clinical medicine. Eczema vaccinatum - a timely reminder. N Engl J Med. 2002;346(17):1287.

73. Vora S, Damon I, Fulginiti V, et al. Severe eczema vaccinatum in a household contact of a smallpox vaccine. Clin Infect Dis. 2008;46(10):1555-61.

74. Kennedy JS, Greenberg RN. IMVAMUNE: modified vaccinia Ankara strain as an attenuated smallpox vaccine. Expet Rev Vaccine. 2009;8(1):13-24.

75. Jordan R, Leeds JM, Tyavanagimatt S, et al. Development of ST- $246^{\circledR}$ for treatment of poxvirus infections. Viruses. 2010;2 (11):2409-35.

76. Tay YK, Khoo BP, Goh CL. The epidemiology of atopic dermatitis at a tertiary referral skin center in Singapore. Asian Pac J Allergy Immunol. 1999;17(3):137-41.

77. Sanderson IR, Brueton LA, Savage MO, et al. Eczema herpeticum: a potentially fatal disease. Br Med J (Clin Res Ed). 1987;294(6573):693-4.

78. Wollenberg A, Zoch C, Wetzel S, et al. Predisposing factors and clinical features of eczema herpeticum: a retrospective analysis of 100 cases. J Am Acad Dermatol. 2003;49:198-205.

79. Frisch S, Siegfried EC. The clinical spectrum and therapeutic challenge of eczema herpeticum. Pediatr Dermatol. 2011;28 (1):46-52.

80. Beck LA, Boguniewicz M, Hata T, et al. Phenotype of atopic dermatitis subjects with a history of eczema herpeticum. J Allergy Clin Immunol. 2009;124(2):260-9.

81. Gao PS, Rafaels NM, Hand T, et al. Filaggrin mutations that confer risk of atopic dermatitis confer greater risk for eczema herpeticum. J Allergy Clin Immunol. 2009;124(3):507-13.

82. Gao PS, Rafaels NM, Mu D, et al. Genetic variants in thymic stromal lymphopoietin are associated with atopic dermatitis and eczema herpeticum. Allergy Clin Immunol. 2010;125(6):1403-7.

83. - De Benedetto A, Slifka MK, Rafaels NM, et al. Reductions in claudin-1 may enhance susceptibility to herpes simplex virus 1 infections in atopic dermatitis. Allergy Clin Immunol. 2011 Jul;128(1):242-246.e5. This is the first report of a novel source of barrier dysfunction in $A D$ - the tight junction.

84. Svejgaard E, Faergeman J, Jemec G, et al. Recent investigations on the relationship between fungal skin diseases and atopic dermatitis. Acta Derm Venereol Suppl (Stockh). 1989;144:140-2.

85. Svejgaard E, Christophersen J, Jelsdorf HM. Tinea pedis and erythrasma in Danish recruits. Clinical signs, prevalence, incidence, and correlation to atopy. J Am Acad Dermatol. 1986;14 (6):993-9.

86. Rajka G. Essential aspects of atopic dermatitis. New York: Springer-Verlag, Berlin Heidelberg; 1989.

87. Hanifin JM, Lobitz WC. Newer concepts of atopic dermatitis. Arch Dermatol. 1977;113:663-70.

88. Akaza N, Akamatsu H, Sasaki Y, et al. Cutaneous Malassezia microbiota in atopic dermatitis patients differ by gender and body part. Dermatology. 2010;221(3):253-60.

89. Darabi K, Hostetler SG, Bechtel MA, et al. The role of Malassezia in atopic dermatitis affecting the head and neck of adults. J Am Acad Dermatol. 2009;60(1):125-36.
90. Brunsting LA. Atopic dermatitis (disseminated neurodermatitis) of young adults. Analysis of precipitating factors in one hundred and one cases and report of ten cases with associated juvenile cataract. Arch Derm Syphilol. 1936;34(6):935-57.

91. Alexander F. Psychosomatic medicine. New York, 1950.

92. Graham DT, Wolf S. The relationship of eczema to attitudes and to vascular reactions of the human skin. J Lab Clin Med. $1953 ; 42: 238-54$.

93. Faulstich ME, Williamson DA, Duchmann EG, et al. Psychophysiological analysis of atopic dermatitis. J Psychosom Res. 1985;29(4):415-7.

94. Absolon CM, Cottrell D, Eldridge SM, et al. Psychological disturbance in atopic eczema: the extent of the problem in school-aged children. Br J Dermatol. 1997;137(2):241-5.

95. Chamlin SL. The psychosocial burden of childhood atopic dermatitis. Dermatol Ther. 2006;19(2):104-7.

96. Daud LR, Garralda ME, David TJ. Psychosocial adjustment in preschool children with atopic eczema. Arch Dis Child. 1993;69 (6):670-6.

97. Roth N, Beyreiss J, Schlenzka K, et al. Coincidence of attention deficit disorder and atopic disorders in children: empirical findings and hypothetical background. J Abnorm Child Psychol. 1991;19(1):1-13.

98. Romanos M, Gerlach M, Warnke A, et al. Association of attention-deficit/hyperactivity disorder and atopic eczema modified by sleep disturbance in a large population-based sample. J Epidemiol Community Health. 2010;64(3):269-73.

99. Schmitt J, Buske-Kirschbaum A, Roessner V. Is atopic disease a risk factor for attention-deficit/hyperactivity disorder? a systematic review. Allergy. 2010;65(12):1506-24.

100. Schmitt J, Chen CM, Apfelbacher C, et al. Infant eczema, infant sleeping problems, and mental health at 10 years of age: the prospective birth cohort study LISAplus. Allergy. 2011;66(3):404-11.

101. Schmitt J, Apfelbacher C, Chen CM, et al. Infant-onset eczema in relation to mental health problems at age 10 years: results from a prospective birth cohort study (German Infant Nutrition Intervention plus). J Allergy Clin Immunol. 2010;125(2):404-10.

102. Yaghmaie P, Koudelka CW, Simpson EL. Psychiatric comorbidity in pediatric eczema. J Invest Dermatol. 2011;131(Supplement 1): S41. Abstract \#246.

103. Hashizume H, Takigawa M. Anxiety in allergy and atopic dermatitis. Curr Opin Allergy Clin Immunol. 2006;6(5):335-9.

104. Boso M, Comelli M, Emanuele E, et al. Seasonal fluctuations in problem behaviors among young adults with autism and intellectual disability. Med Sci Mon. 2010;16(5):CR213-6.

105. Magalhaes ES, Pinto-Mariz F, Bastos-Pinto S, et al. Immune allergic response in Asperger syndrome. J Neuroimmunol. 2009;216(1-2):108-12.

106. Mostofa GA, Hamza RT, El-Shahawi HH. Allergic manifestations in autistic children: relation to disease severity. J Pediatr Neurol. 2008;6(2):115-23.

107. Sacco R, Curatolo P, Manzi B, et al. Principal pathogenetic components and biological endophenotypes in autism spectrum disorders. Autism Res. 2010;3(5):237-52.

108. Yang YW, Tseng KC, Chen YH, et al. Associations among eczema, asthma, serum immunoglobulin $\mathrm{E}$ and depression in adults: a population-based study. Allergy. 2010;65(6):801-2.

109. Dieris-Hirche J, Gieler U, Kupfer JP, et al. Suicidal ideation, anxiety and depression in adult patients with atopic dermatitis. Hautarzt. 2009;60(8):641-6.

110. Yokomaku A, Misao K, Omoto F, et al. A study of the association between sleep habits and problematic behaviors in preschool children. Chronobiol Int. 2008;25(4):549-64.

111. Hiscock H, Canterford L, Ukoumunne OC, et al. Adverse associations of sleep problems in Australian preschoolers: national population study. Pediatrics. 2007;119(1):86-93. 
112. Gregory AM, Van der EJ, Willis TA, et al. Parent-reported sleep problems during development and self-reported anxiety/depression, attention problems, and aggressive behavior later in life. Arch Pediatr Adolesc Med. 2008;162(4):330-5.

113. Owens JA, Maxim R, Nobile C, et al. Parental and self-report of sleep in children with attention-deficit/hyperactivity disorder. Arch Pediatr Adolesc Med. 2000;154(6):549-55.

114. Ivanenko A, Johnson K. Sleep disturbances in children with psychiatric disorders. Semin Pediatr Neurol. 2008;15(2):70-8.

115. Deverman BE, Patterson PH. Cytokines and CNS development. Neuron. 2009;64(1):61-78.

116. Kiecolt-Glaser JK, Belury MA, Andridge R. Omega-3 supplementation lowers inflammation and anxiety in medical students: a randomized controlled trial. Brain Behav Immun. 2011;25(8):1725-34.

117. Pollak Y, Yirmiya R. Cytokine-induced changes in mood and behaviour: implications for "depression due to a general medical condition", immunotherapy and antidepressive treatment. Int $\mathrm{J}$ Neuropsychopharmacol. 2002;5(4):389-99.

118. Zimmerman AW, Jyonouchi H, Comi AM, et al. Cerebrospinal fluid and serum markers of inflammation in autism. Pediatr Neurol. 2005;33(3):195-201.

119. Liezmann C, Klapp B, Peters EM. Stress, atopy and allergy: a reevaluation from a psychoneuroimmunologic perspective. Dermatoendocrinol. 2011;3(1):37-40.

120. Buehler MR. A proposed mechanism for autism: an aberrant neuroimmune response manifested as a psychiatric disorder. Med Hypotheses. 2011;76(6):863-70.

121. Vena JE, Bona JR, Byers TE, et al. Allergy-related diseases and cancer: an inverse association. Am J Epidemiol. 1985;122(1):6674.

122. Wang H, Diepgen TL. Atopic dermatitis and cancer risk. Br J Dermatol. 2006;154(2):205-10.

123. Merrill RM, Isakson RT, Beck RE. The association between allergies and cancer: what is currently known? Ann Allergy Asthma Immunol. 2007;99(2):102-16. quiz 117-119.

124. Vajdic CM, Falster MO, de Sanjose S, et al. Atopic disease and risk of non-Hodgkin's lymphoma; an InterLymph pooled analysis. Cancer Res. 2009;69:6482-9.

125. Arana A, Wentworth CE, Fernóndez-Vidaurre $C$, et al. Incidence of cancer in the general population and in patients with or without atopic dermatitis in the U.K. Br J Dermatol. 2010;163:1036-43.

126. Hwang CY, Chen YJ, Lin MW, et al. Cancer risk in patients with allergic rhinitis, asthma and atopic dermatitis: a nationwide cohort study in Taiwan. Int J Cancer. 2011. doi:10.1002/ijc. 26105.

127. Tennis P, Gelfand JM, Rothman KJ. Evaluation of cancer risk related to atopic dermatitis and use of topical calcineurin inhibitors. Br J Dermatol. 2011;165(3):465-73.

128. Wedgeworth E, Powell AM, Flohr C. Eczema and cancer risk: a critical appraisal and review of the literature. Br J Dermatol. 2011;165(3):457-62. discussion 462-463.

129. Wedgeworth E, Powell AM, Flohr C. Incidence of cancer in the context of atopic dermatitis. Br J Dermatol. 2011;164(4):896-7. authors' reply $897-898$.
130. Dandona P, Aljada A, Bandyopadhyay A. Inflammation: the link between insulin resistance, obesity and diabetes. Trends Immunol. 2004;25(1):4-7.

131. Procaccini C, Carbone F, Galgani M, et al. Obesity and susceptibility to autoimmune diseases. Expert Rev Clin Immunol. 2011;7(3):287-94.

132. Yoo S, Kim HB, Lee SY, et al. Association between obesity and the prevalence of allergic diseases, atopy, and bronchial hyperresponsiveness in Korean adolescents. Int Arch Allergy Immunol. 2011;154(1):42-8.

133. Figueroa-Munoz JI, Chinn S, Rona RJ. Association between obesity and asthma in 4-11 year old children in the UK. Thorax. 2001;56:133-7.

134. von Kries R, Hermann M, Grunert VP, et al. Is obesity a risk factor for childhood asthma? Allergy. 2001;56:318-22.

135. von Mutius E, Schwartz J, Neas LM, et al. Relation of body mass index to asthma and atopy in children: the National Health and Nutrition Examination Study III. Thorax. 2001;56:835-8.

136. Kusunoki T, Morimoto T, Nishikomori R, et al. Obesity and the prevalence of allergic diseases in schoolchildren. Pediatr Allergy Immunol. 2008;19(6):527-34.

137. Palit A, Handa S, Bhalla AK, et al. A mixed longitudinal study of physical growth in children with atopic dermatitis. Indian $\mathrm{J}$ Dermatol Venereol Leprol. 2007;73(3):171-5.

138. Kristmundsdottir F, David TJ. Growth impairment in children with atopic eczema. J R Soc Med. 1987;80(1):9-12.

139. Massarano AA, Hollis S, Devlin J, et al. Growth in atopic eczema. Arch Dis Child. 1993;68:677-9.

140. Pike MG, Chang CL, Atherton DJ, et al. Growth in atopic eczema: a controlled study by questionnaire. Arch Dis Child. 1989;64:1566-9.

141. Patel L, Clayton PE, Addison GM, et al. Linear growth in prepubertal children with atopic dermatitis. Arch Dis Child. 1998;79:169-72.

142. Patel L, Clayton PE, Jenney ME, et al. Adult height in patients with childhood onset atopic dermatitis. Arch Dis Child. 1997;76:5058.

143. Ellison JA, Patel L, Kecojevic T, et al. Pattern of growth and diposity from infancy to adulthood in atopic dermatitis. Br J Dermatol. 2006;155(3):532-8.

144. Silverberg JI, Kleiman E, Lev-Tov H, et al. Association between obesity and atopic dermatitis in childhood: a case-control study. J Allergy Clin Immunol. 2011;127(5):1180-1186.e1.

145. Silverberg JI, Silverberg NB, Lee-Wong M. Association between atopic dermatitis and obesity in adulthood. Br J Dermatol. 2011. doi:10.1111/j.1365-2133.2011.10694.x. Epub ahead of print.

146. Vlaski E, Stavric K, Isjanovska R, et al. Overweight hypothesis in asthma and eczema in young adolescents. Allergol Immunopathol (Madr). 2006;34:199-205.

147. Violante R, del Rio Navarro BE, Berber A, et al. Obesity risk factors in the ISAAC (International Study of Asthma and Allergies in Childhood) in Mexico City. Rev Alerg Mex. 2005;52:141-5. 